\title{
The transition towards an environmental sustainability for Cryptocurrency mining
}

\author{
Ioan Bitir-Istrate ${ }^{1}$, Cristian Gheorghiu, ${ }^{2, *}$, and Miruna Gheorghiu ${ }^{3}$ \\ ${ }^{1}$ University Politehnica of Bucharest, Energy Production and Use Department, $313^{\text {th }}$ Splaiul Independenței, Bucharest, Romania \\ ${ }^{2}$ University Politehnica of Bucharest, Energy Production and Use Department, $313^{\text {th }}$ Splaiul Independenţei, Bucharest, Romania \\ ${ }^{3}$ Elsaco ESCO L.L.C., $500^{\text {th }}$ Mihai Bravu Boulevard, Bucharest, Romania
}

\begin{abstract}
As Cryptocurrency becomes more and more popular so does its demand for mining rigs. At the end of 2020 there were approximately 5,392 different cryptocurrencies available with a total market capitalization of more than $\$ 201 \mathrm{bn}$ [1]. Cryptocurrencies are using decentralized, distributed systems in order to operate. The mining process involves solving cryptographic equations, which are ultimately used for ensuring encryption of the blockchain transactions, through the use of IT equipment - the most efficient way of doing it being by building mining farms which use Graphics Processing Units (GPUs). The Crypto farmers are rewarded with a share of the transaction they facilitate. As the Cryptocurrency market grows exponentially every year, so does its hunger for energy. For example, the Bitcoin Energy Consumption Index is evaluated to reach $77.782 \mathrm{TWh} /$ year in 2021 [2], which, for comparison, is approximately 1.5 times larger than the entire electricity consumption of Romania in 2020 [3]. In this paper, the transition of Cryptocurrency mining processes towards environmental sustainability will be analysed. A Crypto-farm's Energy Performance Indicators (EPI) and Power Quality Indices (PQI) will be evaluated and, with the use of dedicated software solutions, the authors will propose an action plan to minimize the environmental impact of the energy boundary and to maximize the EPI, thus maximizing the profitability of this new type of business.
\end{abstract}

\section{Energy boundary description}

The case study is a cryptocurrency farm located in Bucharest, in a warehouse that was retrofitted for this business. The warehouse has a useful surface of $4,000 \mathrm{~m}^{2}$.

As cryptocurrency transactions are based on a public key encryption, also known as an asymmetric encryption. Cryptocurrencies use a decentralized ledger known as blockchain, which is essentially a series of chained data blocks that contain key pieces of data, including cryptographic hashes.

The creation of blockchain requires the existence of nodes (individual devices that exist within the blockchain), miners (specific nodes that verify (solve) unconfirmed blocks in the blockchain by verifying the hashes, transactions (separate transactions are bundled and form a list that gets added to an unconfirmed block), hashes (one-way cryptographic functions used by nodes to verify the legitimacy of transactions which are generated by combining the header data from the previous blockchain block with a nonce), a consensus algorithm (a protocol within blockchain which helps different nodes come to an agreement whilst verifying data - Proof of Work and blocks (individual sections that contains a list of completed transactions - a block that was verified cannot be later modified).

The cryptocurrency mining business is extremely dependent on the mining power of the rigs as the process implies that the farm has to constantly verify cryptocurrency transactions by decrypting crypto blocks (usually $1 \mathrm{MB}$ of data / block - which can usually contain several thousand transactions). The verification / decryption process is rewarded with a small share of the cryptocurrency as long as the proof of work or hash is obtained.

The hash is a 64-digit hexadecimal number that is less than or equal to the target hash (transaction encryption). It can be thus concluded that the Hash-rate $(\mathrm{MH} / \mathrm{s}, \mathrm{GH} / \mathrm{s}$, $\mathrm{TH} / \mathrm{s}$ ) of the mining rig severely impacts the economic efficiency of the business.

The Capital Expenditures (CAPEX) for setting up the business are estimated at 450,000 EUR, out of which the actual implementation costs (IC) were approximatively 100,000 EUR and included retrofitting the existing electricity distribution network of the warehouse, installing ventilation modules, ICT network design and installation and programming the GPU's.

The rest of 300,000 EUR were used for building the mining rigs. The farm is made up of 100 rigs, as presented in Fig. 1, out of which:

$>30$ rigs have 13 Nvidia P104-100 8 GB Ram and MB Asus B250 Mining Expert 4 GB Ram, 120 GB SSD Memory and an IBM 2,880W power supply. These rigs mine ETH (Ethereum) at $470 \mathrm{MH} / \mathrm{s}$ with an average electricity use of $2 \mathrm{kWh} / \mathrm{h}$. Each rig mines $0.9 \mathrm{ETH} / \mathrm{month}$;

\footnotetext{
* Corresponding author: cristian.gheorghiu@upb.ro
} 
> 70 rigs have 6 AMD RX 5808 GB Ram, 120 GB SSD Memory and an HP 1,200 W Power Supply. These rigs mine ETH at $200 \mathrm{MH} / \mathrm{s}$ with an average electricity use of $1 \mathrm{kWh} / \mathrm{h}$. Each rig mines 0.4 $\mathrm{ETH} / \mathrm{month}$.

The ventilation system is made up of 44 high capacity fans with a rated power of $0,75 \mathrm{~kW}$. This leads to a low efficiency cooling of the mining rigs.

The warehouse lighting system is comprised of 10 LED lamps with an installed power or 150W/lamp. The warehouse also has a close circuit tv (CCTV) system.

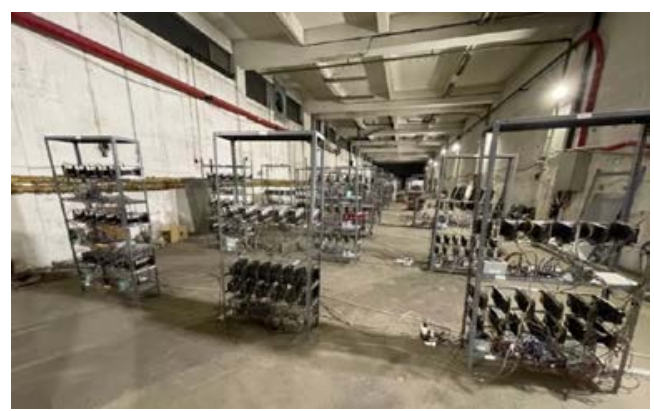

Fig. 1. Cryptocurrency farm overview (Ventilation system not shown)

The total cryptocurrency mining capacity of the system is of approximatively $55 \mathrm{ETH} / \mathrm{month}$. At a price of 2,007.74 USD/ETH, the monthly generated income is $110,425.70 \quad$ USD/month, respectively 1,099,840 EUR/year. The viability of the business if also proven by the evolution of ETH in the last 12 months, as seen in Fig.1.

Considering an 8,600 hours/year operation time, the average yearly electricity use for the mining rigs is 1,123.2 MWh/year. The existing ventilation system has an average yearly electricity use of $171 \mathrm{MWh}$ /year. The total yearly electricity use is approximatively 1,294.27 $\mathrm{MWh} /$ year . As the warehouse has a medium voltage connection via a $400 \mathrm{kVA}$ power transformer, the electricity price is approximatively 70 EUR/MWh. Considering ICT maintenance and periodical upgrades of the system, which amount to 5,000 EUR/month, the yearly operational costs (OPEX) rise to an average of 150,599 EUR/year.

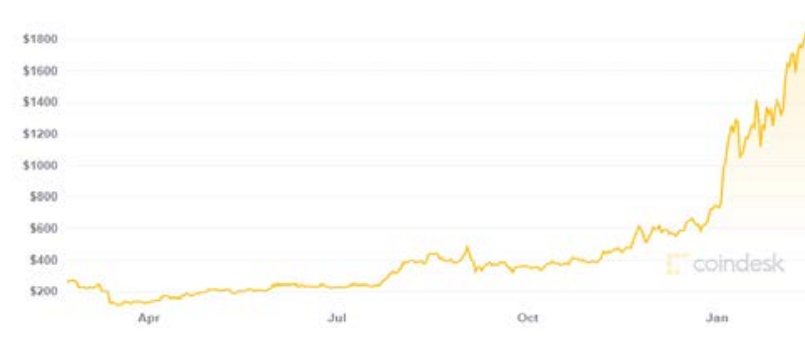

Fig. 2. ETH price evolution 20.02.2020 - 20.02.2021 [4]

\section{Energy Performance Analysis}

The first step in proposing a practical guide for transitioning towards an environmental sustainability for the Cryptocurrency mining business is to properly establish the energy baseline and the energy performance baseline for the analysed energy boundary.
In order to do so, firstly, relevant EPI's to be determined must be selected.

Considering that the energy boundary has no need for any other form of energy except electricity, the most relevant EPI is the specific electricity use ( $\left.W_{s p}^{e}\right)$, determined with equation (1):

$$
W_{s p}^{e}=\frac{W^{e}}{E T H}\left[\frac{M W h}{E T H}\right]
$$

where $W^{e}[\mathrm{MWh} / \mathrm{year}]$ is the annual electricity use and ETH [ETH/year] is the yearly ETH generated by the mining rigs.

The environmental sustainability of the business can be evaluated by determining the specific equivalent $\mathrm{CO}_{2}$ emissions generated over a year $\left(A_{s p}^{\mathrm{CO}_{2}}\right)$, with equation (2):

$$
A_{s p}^{\mathrm{CO}_{2}}=\frac{A^{\mathrm{CO}_{2}}}{E T H}\left[\frac{\text { tons } \mathrm{CO}_{2, e q}}{E T H}\right]
$$

where $A^{C_{2}}$ [tons $\mathrm{CO}_{2, \mathrm{eq}} /$ year] is the annual $\mathrm{CO}_{2}$ equivalent greenhouse gases emission determined by using the average conversion factor for Romania of 355 $\mathrm{gCO}_{2, \mathrm{eq}} / \mathrm{kWh}[5]$.

The global EPI used was Energy Intensity (EI) which was determined by using equation (3):

$$
E I=\frac{E E}{P V}\left[\frac{t . o . e .}{E U R \cdot 10^{3}}\right]
$$

where $E E$ [t.o.e./year] is the annual equivalent energy use of the energy boundary, expressed in tons of oil equivalent (t.o.e.) and $P V$ [thousand EURs/year] is the yearly production / income generated.

A fourth relevant EPI used in order to financially quantify the sustainability of the business is the specific $\mathrm{CO}_{2}$ equivalent emission reported to the yearly production / income, determined with equation (4).

$$
A_{g}^{\mathrm{CO}_{2}}=\frac{A^{\mathrm{CO}_{2}}}{P V}\left[\frac{\text { tons } \mathrm{CO}_{2, e q}}{\mathrm{EUR} \cdot 10^{3}}\right]
$$

The resulting baseline EPI's are presented in Table 1.

Table 1. Baseline EPI values

\begin{tabular}{|c|c|c|}
\hline EPI & Value & Measuring Unit (M.U.) \\
\hline$W_{s p}^{e}$ & 1.96 & $\mathrm{MWh} / \mathrm{ETH}$ \\
\hline$A_{s p}^{C O_{2}}$ & 0.70 & tons $\mathrm{CO}_{2, \mathrm{eq}} / \mathrm{ETH}$ \\
\hline$E I$ & 0.0840 & t.o.e./thousand EUR \\
\hline$A_{g}^{C O_{2}}$ & 0.418 & tons $\mathrm{CO}_{2, \text { eq }} /$ thousand EUR \\
\hline
\end{tabular}

As it can be observed, the EI of the cryptocurrency mining business is similar to various other production sector business, with an average variation range of $0.06-$ 0.1 t.o.e. per thousand EUR, close to the global average of 0.134 t.o.e. per thousand EUR [6].

\section{Power Quality Analysis}

As the energy boundary is powered by a $400 \mathrm{kVA}$ Power Transformer that also ensures the power supply of 2 other warehouses, in order to properly analyse the Power Quality influence of the mining rigs, without overlapping electromagnetic perturbances and multiple PQI values in the point of common coupling, the PQI analysis was done over a period of time in which only the cryptocurrency farm was operating. 
By using a Chauvin Arnoux C.A. 8336 Power Quality and Energy Analyzer in the Point of Common Coupling (PCC) over a period of 7 days, the following PQI values, presented in Table 2 and Table 3, were measured / determined.

Table 2. PQI Values

\begin{tabular}{|c|c|c|}
\hline PQI & Value & M.U. \\
\hline & 393.86 & \\
Voltage & 396.16 & $\mathrm{~V}$ \\
& 392.10 & \\
\hline & 90.05 & \\
Current & 98.98 & $\mathrm{~A}$ \\
& 105.05 & \\
\hline Frequency & 49.99 & $\mathrm{~Hz}$ \\
\hline Power Factor & 0.23 & - \\
\hline Voltage Total & 2.92 & \\
Harmonic Distorsion & 2.75 & $\%$ \\
Factor (THDv) & 2.56 & \\
\hline Current Total & 115.93 & \\
Harmonic Distorsion & 146.26 & $\%$ \\
Factor (THDI) & 182.43 & \\
\hline
\end{tabular}

Table 3. PQI Testing

\begin{tabular}{|c|c|}
\hline PQI Limits & PASS TEST \\
\hline Voltage: $400 \pm 10 \%$ V [7] & Yes \\
\hline Frequency: $50 \pm 1 \% \mathrm{~Hz}[8]$ & Yes \\
\hline Power Factor: $0.90^{\mathrm{a} .}$ & No \\
\hline THDv $: 8 \%[9]$ & Yes \\
\hline THD $: 20 \%[10]$ & No \\
\hline
\end{tabular}

bill

a. Set by the end-user in order to minimize the reactive energy

As it can be observed in Table 3, the analysed energy boundary failed to pass the THDI test [10] and the Power Factor Test ${ }^{\mathrm{a}}$.

The other PQI limits were easily respected by all CNC machines.

As [11] has demonstrated, the abnormally large $\mathrm{THD}_{\mathrm{I}}$ values are generated by the power sources which ensure the DC power to the mining rigs.

However, as proven in [12], $\mathrm{THD}_{\mathrm{I}}$ values are highly impacting the energy losses in the Power Transformer.

The influence of the current harmonics on the overall energy losses can be determined by applying equation (5):

$$
\begin{array}{r}
\Delta P_{\text {single phase }}=R_{\text {net }} \cdot I^{2} \\
=R_{\text {net }} \cdot\left(I_{1}^{2}+\sum_{n=2}^{\infty} I_{n}^{2}\right)[W] \\
\Delta P_{\text {single phase }}=R_{\text {net }} \cdot I_{1}^{2} \cdot\left(1+T H D I_{I}^{2}\right)[W]
\end{array}
$$

where Rnet $[\Omega]$ is the analysed networks resistance, determined with (6), $\mathrm{I}_{1}$ [A] is the average fundamental root-mean-square value of the electrical current, $I_{n}[A]$ is the average root-mean-square value of the nth rank current harmonic and $\mathrm{THD}_{\mathrm{I}}[\%]$ is the average measured total current harmonic distortion factor.

$$
R_{\text {net }}=r_{0} \cdot l_{\text {net }}+R_{T}[\Omega]
$$

where $r_{0}[\Omega / \mathrm{km}]$ is the specific resistance of the electric wires, $l_{\text {net }}[\mathrm{km}]$ is the length of the considered electric network and $R_{T}[\Omega]$ is the power transformer internal resistance.

\section{Energy Performance Improvement Actions}

The main issues identified within the analysed energy boundary are presented in Table 4.

Table 4. EPI / PQI atual status

\begin{tabular}{|c|c|c|c|}
\hline Indicator & Value & Issue & Impact \\
\hline$E I$ & 0.0840 & Large & $\begin{array}{c}\text { High Electricity Use } \\
\text { High Environmental Impact }\end{array}$ \\
\hline$P F$ & 0.23 & Small & $\begin{array}{c}\text { High Reactive Energy Input } \\
\text { Lowers the transit capacity of } \\
\text { the local distribution grid }\end{array}$ \\
\hline$T H D_{I}$ & 148.2 & Large & $\begin{array}{c}\text { Additional Losses in the power } \\
\text { distribution grid, High } \\
\text { Environmental Impact }\end{array}$ \\
\hline
\end{tabular}

To mitigate the various issues identified in the energy analysis stage, the EPIAs presented in Table 5 were evaluated from a technical and economical point of view.

Table 5. EPIA proposals

\begin{tabular}{|c|c|}
\hline EPIA & Impact \\
\hline $\begin{array}{c}\text { Modernizing the cooling } \\
\text { system }\end{array}$ & $\begin{array}{c}\text { Reduce Electricity Use } \\
\text { Dimish the environmental } \\
\text { impact }\end{array}$ \\
\hline $\begin{array}{c}\text { Implementing a } \\
\text { photovoltaic (PV) system }\end{array}$ & $\begin{array}{c}\text { Diminish the environmental } \\
\text { impact }\end{array}$ \\
\hline $\begin{array}{c}\text { Installing Active Filters in } \\
\text { the PCC }\end{array}$ & $\begin{array}{c}\text { Improving PQI values } \\
\text { Diminish the environmental } \\
\text { impact }\end{array}$ \\
\hline
\end{tabular}

The main criterions used in the technic and economic analysis of the EPIAs were the Net Present Value - NPV (7), the Internal Rate of Return - IRR (8), the Simple Payback Period (9), determined by considering a variable annual net income and the Benefit - Cost Analysis - BCA (10).

$$
N P V=\sum_{t=1}^{t s t} \frac{I_{t}-C_{t}}{(1+a)^{t}}-I C[E U R]
$$

where $t_{\text {tst }}$ is the analysis time-frame, in years, selected as per [13], $I_{t}$ is the yearly income in the $t^{\text {th }}$ year, in EUR/year, $C_{t}$ are the yearly expenditures in the $t^{\text {th }}$ year, in EUR/year, a is the discount rate $-9.86 \% /$ year for this enduser and IC is the investment cost, in EUR.

$$
N P V=\sum_{t=1}^{t s t} \frac{I_{t}-C_{t}}{(1+I R R)^{t}}=0[E U R]
$$

where the CAPEX can be included in the yearly expenditures as a depreciation cost.

$$
\begin{gathered}
S P P=\frac{I C}{\frac{\sum_{i=1}^{t} I_{i}-C_{i}}{t}} \text { [years] } \\
B C A=\frac{I C}{N P V}[-]
\end{gathered}
$$

An average escalation rate for electricity prices of $5 \% /$ year was also considered, as determined in [14].

The actual cooling system should be replaced with a centralized high efficiency cooling system, as displayed in Fig. 3. The Hot-Aisle Containment System (HACS) was proposed as it has been proven to lower the electricity use by up to $40 \%$ compared to the Cold-Aisle Containment System (CACS).

This system also allows for an optimization of the space in the warehouse, where all the 100 mining rigs will 
be included in a single HACS by regrouping the GPUs in order to minimize the number of racks required.

The IC of this EPIA is approximatively 30,000 EUR. The yearly $C_{t}$ is estimated at 2,000 EUR/year. The annual electricity use of the system is estimated to be of up to 90 $\mathrm{MWh}$ /year. The timeframe analysis was considered to be 10 years.
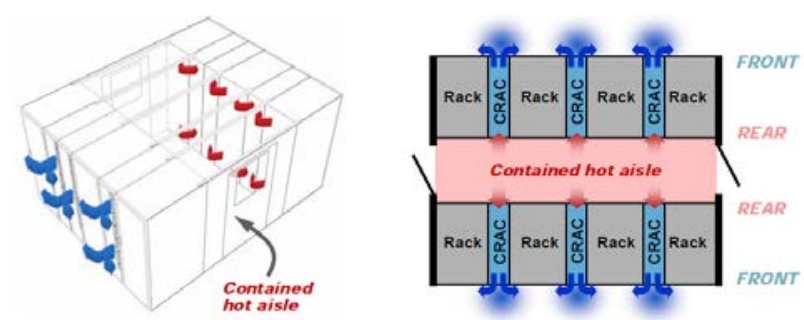

Fig. 3. Hot Aisle Containment Cooling System [15]

As the warehouse is the end-user's propriety, the PV System can be installed on it's roof. The proposed PV System will be presented in Table 6. By using RETScreen Expert software the estimated efficiency and expected electricity production were determined. The simulation results are also presented in Table 6.

Table 6. PV System and Simulation results

\begin{tabular}{|c|c|c|}
\hline Component & Value & M.U. \\
\hline PV Panel type & CS3W-410P & - \\
\hline Panel rated Power & 410 & $\mathrm{Wp}$ \\
\hline Rated efficiency & 18.56 & $\%$ \\
\hline Installation angle & 30 & ${ }^{\circ}$ \\
\hline Technical waranty & 25 & Years \\
\hline Quantity & 1,000 & Pcs. \\
\hline System Peak Power & 400 & $\mathrm{~kW}$ \\
\hline Inverter rated power & 100 & $\mathrm{~kW}$ \\
\hline Number of Inverters & 4 & Pcs. \\
\hline Expected electricity production & 595.307 & MWh/year \\
\hline
\end{tabular}

Considering an investment cost of $656 \mathrm{EUR} / \mathrm{kWp}$, as determined by the authors consultancy experience, the total IC for the EPIA is of approximatively 262,400 EUR. The $C_{t}$ for the PV system will be less than 2,500 EUR/year, as the system will not be exposed to excessive dusting and as Bucharest does not have particularly heavy winters or significant number of hailstorms.

Installing an Active Filter (see Fig. 4) in the PCC will generate an additional IC of approximatively 23,000 EUR with an annual $\mathrm{C}_{t}$ of 3,000 EUR/year. By implementing this EPIA the end-user will obtain a $\mathrm{THD}_{\mathrm{I}}$ reduction of up to $90 \%$ and a PF improvement of up to 0.92 , thus minimizing the reactive energy bill. The actual reactive energy bill is approximatively 1,500 EUR/month. The timeframe analysis was considered to be 6 years.

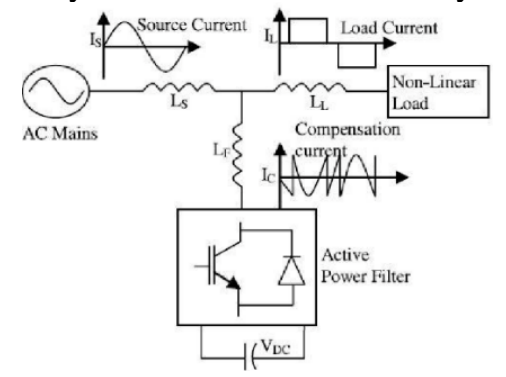

Fig. 4. Active Power Filter (APF) [16]
The reduction of the $\mathrm{THD}_{\mathrm{I}}$ will also lead (as per equation (5) and (6)) to a decrease in the total active energy losses of up to $18 \%$, which amounts to approximatively $30 \mathrm{MWh} /$ year.

The Technical and Economic Analysis results for all three EPIAs will be presented in Table 7.

Table 7. EPIA Economic Analysis results

\begin{tabular}{|c|c|c|c|c|}
\hline EPIA & $\begin{array}{c}\text { NPV } \\
\text { [EUR] }\end{array}$ & $\begin{array}{c}\text { IRR } \\
\text { [\%] }\end{array}$ & $\begin{array}{c}\text { SPP } \\
\text { [years] }\end{array}$ & $\begin{array}{c}\text { BCA } \\
{[-]}\end{array}$ \\
\hline HACS & 1,717 & 12 & 7.33 & 1.06 \\
\hline PV System & 325,138 & 20 & 6.62 & 2.24 \\
\hline APF & 53,396 & 73 & 2.33 & 3.32 \\
\hline
\end{tabular}

As it can be observed from Table 7, all three EPIA’s lead to positive financial results over the study period. The end-user should be highly motivated to implement all three EPIA's as the total NPV reaches 380,251 EUR.

\section{Sustainability Improvement Analysis}

By implementing the Energy Performance Improvement Plan (EPIP) presented in Chapter 5, a major Environmental Impact Reduction (EIR) will also be achieved.

In order to quantify the yearly and life-cycle EIR, the methodology presented in [5] was used. The electricity conversion factor of $355 \mathrm{gCO}_{2}$ equivalent $/ \mathrm{kWh}$ was considered. The conversion factor also considers the energy losses in the national power grid, which for Romania are situated at approximatively $7 \%$ for a Low Voltage (LV) internal distribution grid.

The EIR was determined and will be presented in Table 8.

As it can be observed, by implementing the EPIP, the end-user can obtain a total EIR of 250.38 tons of $\mathrm{CO}_{2}$ equivalent / year, respectively 5,631.25 tons of $\mathrm{CO}_{2}$ equivalent for the EPIP Lifecycle.

The EIR amounts to approximatively 54.49 of the annual $\mathrm{CO}_{2}$ equivalent emissions. This will lead to an overall improvement of the $A_{g}^{C_{2}}$ to a value of 0.19 tons of $\mathrm{CO}_{2}$ equivalent per thousand of EUR of income.

Table 8. EPIA Economic Analysis results

\begin{tabular}{|c|c|}
\hline EPIA & EIR [tons $\mathbf{C O}_{\mathbf{2}} \mathbf{e q} /$ year] \\
\hline HACS & 28.40 \\
\hline PV System & 211.33 \\
\hline APF & 10.65 \\
\hline TOTAL & $\mathbf{2 5 0 . 3 8}$ \\
\hline
\end{tabular}

\section{Conclusions}

If a linear electricity use escalation with regard to mining capacity is considered when analysing the Cryptocurrency Mining businesses, it is strongly recommended that a novel regulatory framework should be developed.

Considering the ETH mining power use (24.26 TWh/year), presented in Fig. 5, by extending the implementation of the proposed EPIP to the whole sector, an overall EIR of up to 4,693,230 tons of $\mathrm{CO}_{2}$ equivalent/year, which represents $5 \%$ of all of Romania's latest reported $\mathrm{CO}_{2}$ emissions. 


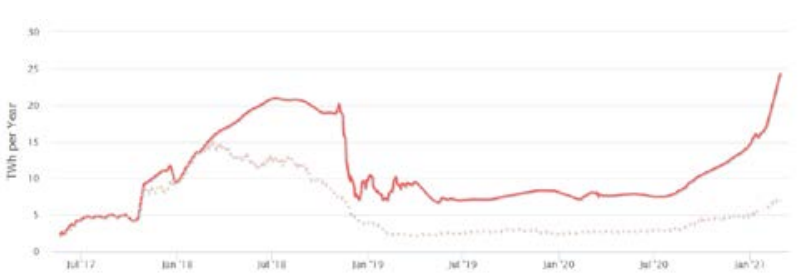

Fig. 5. ETH Energy Consumption Index [17]

As digitalization progresses at a faster than ever rate, a transition towards an environmental sustainability for Cryptocurrency mining policy is required to ensure the organic and ecological development of this sector.

The regulatory framework should guide both new crypto-miners and existing ones in optimizing their electricity use and minimizing their Environmental Impact.

Rules and regulations regarding the necessity of ensuring at least $50 \%$ of the electricity use by means of using alternative, clean, energy sources and the necessity to use Best Available Technologies (BAT) when equipping the cryptocurrency farm should also be drafted up as soon as possible the national, European and International policy makers.

If every cryptocurrency mining business owner will always choose the BAT regarding the GPUs and Power Supply, the same cannot be stated about lighting, cooling and power quality mitigation. The new cryptocurrency policy should mandate the minimum efficiency level that is acceptable for these three types of equipment, in order to fully optimize the electricity use in the individual energy boundaries.

\section{References}

1. https://finance.yahoo.com/news/top-10cryptocurrencies-market-capitalisation160046487.html, accessed 02.01.2021

2. Alex de Vries, "Bitcoin's energy consumption is underestimated: A market dynamics approach," Energy Research \& Social Science, Vol. 70, https://doi.org/10.1016/j.erss.2020.101721 (2020)

3. Enerdata, “Romania Energy Report,” (2020)

4. https://www.coindesk.com/price/ethereum, accessed 20.02.2021

5. European Investment Bank, "EIB Project Carbon Footprint Methodologies: Methodologies for the Assessment of Project GHG Emissions and Emission Variations," (2020)

6. International Energy Agency, "Energy Efficiency Indicators”, https://www.iea.org/reports/energyefficiency-indicators, (2020)

7. International Electrotechnical Commission, "IEC 61000-3-3 Electromagnetic Compatibility - Part 3-3: Limits - Limitation of voltage changes, voltage fluctuations and flicker in public low voltage supply systems, for equipment with rated current 16 A per phase and not subject to conditional connection," (2013).

8. Energy National Regulatory Agency, "Order no. 49/2017 for modifying the Power Distribution Services Performance Standard,” National Gazette, Part 1, No. 535, (2017).

9. International Electrotechnical Commission, "IEC 61000 group of standards” (2016).

10. Institute of Electrical and Electronics Engineers,"IEEE 519-2014 Recommended Practices and Requirements for Harmonic Control in Electrical Power Systems,” (2014).

11. A.M. Blanco, J. Meyer, A. Pavas, C.A. Garzon, M. Romero and P. Schegner, "Harmonic distortion in public low-voltage grids Comparison of the situation in Colombia and Germany," Ingineria e Investigacion, Vol. 35, Sup. No.1, pp. 50-57, (2015).

12. C. Gheorghiu, M. Scripcariu, S. Gheorghe and R. Porumb, "Energy Efficiency and Power Quality Indicators of a Micro Grid. Case Study: Lighting Systems," 8th International Conference on Modern Power Systems (MPS), DOI: 10.1109/MPS.2019.8759734, (2019).

13. The Romanian Government, "Decision no. 2139/30.10.2004 for approving the normal period of use for capital goods,” Official Gazette, Part I, No. 46/13.01.2005.

14. Ioan-Sevastian Bitir-Istrate, Cristian Gheorghiu and Miruna Gheorghiu, "The Cost of Indecision in Energy Efficiency. A Cost of Opportunity Analysis for an Industrial Consumer," 55th International Scientific Conference on Information, Communication and Energy Systems and Technologies (ICEST), DOI: 10.1109/ICEST49890.2020.9232894, (2020).

15. John Niemann, Kevin Brown and Victor Avelar," Hot-Aisle vs. Cold-Aisle Containment for Data Centers," Schenider Electric, American Power Conversion, West Kingston, RI, White Paper No. 135, (2008).

16. Kouadria, Abdeldjabbar Mohamed and T. Allaoui. "Adaptive Hysteresis Band Based Fuzzy Controlled Shunt Active Power Filter.” International Conference on Industrial Engineering and Operations Management (IEOM), (2017).

17. https://digiconomist.net/ethereum-energyconsumption/, accessed 01.03.2021. 